\section{Commentary: In harm's way: The circumflex artery and mitral surgery}

\author{
Patrick M. McCarthy, MD
}

For decades, we have known that the circumflex artery may run a course close to the mitral valve annulus and is at risk of injury during a mitral valve procedure. The article by Caruso and colleagues ${ }^{1}$ adds to the body of knowledge by reporting on 95 patients who underwent coronary computed tomography (CT) angiography with calculations made of the distance from the circumflex artery to the posterior mitral annulus between the commissures. They divided this into 5 zones and, unsurprisingly, found that the closest distance was between the anterolateral commissure and along segment P1. What was surprising was just how close the artery was in that high-risk zone (defined as $<3 \mathrm{~mm}$ ), with $25 \%$ falling into that range and a mean distance of only $1.94 \pm 0.8 \mathrm{~mm}$. In addition, as expected, the left dominant and codominant circulations had a shorter distance along each zone.

So what do we do with these data? The authors suggest that choosing a sternotomy instead of right thoracotomy approach may be warranted in the high-risk group. Circumflex injury certainly creates a difficult clinical scenario when performing surgery via thoracotomy. ${ }^{2}$ That is a prudent choice. But there is a disconnect between the $25 \%$ risk and the actual perceived low occurrence of perioperative myocardial infarction (MI). Most enthusiasts of the right thoracotomy approach, and mitral surgeons in general, observe a $1 \%$ to $2 \%$ occurrence of perioperative MI. No

From the Division of Cardiac Surgery, Department of Surgery, Bluhm Cardiovascular Institute, Northwestern University Feinberg School of Medicine and Northwestern Medicine, Chicago, Ill.

Disclosures: Dr McCarthy serves as a consultant for and receives royalties from Edwards Lifesciences, receives honoraria from AtriCure and Medtronic, and serves as the Surgical Principal Investigator for the REPAIR-MR trial which is an unfunded position.

The Journal policy requires editors and reviewers to disclose conflicts of interest and to decline handling or reviewing manuscripts for which they may have a conflict of interest. The editors and reviewers of this article have no conflicts of interest.

Received for publication Oct 20, 2020; revisions received Oct 20, 2020; accepted for publication Oct 20, 2020; available ahead of print Oct 23, 2020.

Address for reprints: Patrick M. McCarthy, MD, Division of Cardiac Surgery, Northwestern University, 676 North Saint Clair St, Suite 730, Chicago, IL 60611 (E-mail: Patrick.McCarthy@nm.org).

JTCVS Techniques 2020;4:132

2666-2507

Copyright $(2020$ The Authors. Published by Elsevier Inc. on behalf of The American Association for Thoracic Surgery. This is an open access article under the CC BY-NCND license (http://creativecommons.org/licenses/by-nc-nd/4.0/).

https://doi.org/10.1016/j.xjtc.2020.10.019

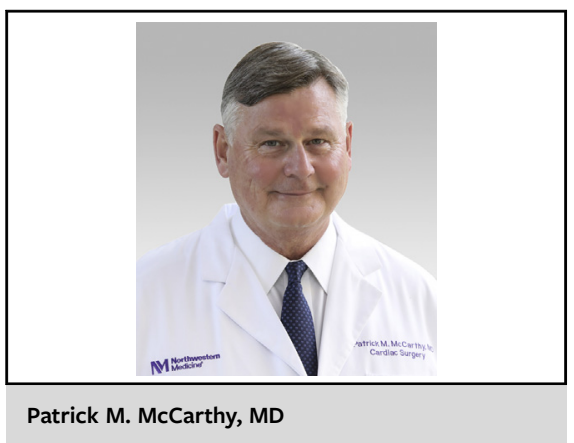

CENTRAL MESSAGE

From the anterior commissure, along $\mathrm{P}_{1}$, the distance of the circumflex artery to the mitral annulus was high risk for injury in 25\% (1.94 $\pm 0.8 \mathrm{~mm})$. Proper suture placement is key to avoid injury.

technique can eliminate the risk of circumflex injury, but it can be reduced from $25 \%$ by attention to detail. In any surgical approach, proper suture placement is key, and in each case the surgeon should assume that the circumflex is at risk near the commissure and P1 (and P2 for patients with a left dominant circulation). Thus, preoperative coronary CT angiography is not necessary. The repair sutures should enter and exit the tissue as close as possible and into the annular tissue, using various needle loads and angles to accomplish this, but avoiding suture placement into leaflet tissue, as the leaflet may tear and lead to an mitral regurgitation jet that hits the ring and causes hemolysis. Replacement sutures should enter through the annulus or on the edge of the annulus, and the needle should exit through the annulus or free edge of the remaining leaflet tissue (in a chord-sparing procedure). There are many potential pitfalls in mitral surgery; this report reminds us of a common concern and provides excellent new data.

\section{References}

1. Caruso V, Shah U, Sabry H, Gedela S, Birdi I. Mitral valve annulus and circumflex artery: in vivo study of anatomical zones. J Thorac Cardiovasc Surg Tech. 2020;4: 122-9.

2. Banayan J, Dhawan R, Vernick WJ, McCarthy PM. CASE 3-2012. Iatrogenic circumflex artery injury during minimally invasive mitral valve surgery. $J$ Cardiothorac Vasc Anesth. 2012;26:512-9. 